\title{
Investigating extemporaneous compounding practices in the Polokwane tertiary hospital pharmacies in South Africa - a pilot study
}

\author{
Euphenia Mathebule Masupye $^{1,2}$, Fatima Suleman ${ }^{2 \star}$ and Thirumala Govender ${ }^{2}$ \\ ${ }^{1}$ Department of Pharmacy, University of Limpopo, Turfloop Campus, South Africa. \\ ${ }^{2}$ Discipline of Pharmaceutical Sciences, University of KwaZulu-Natal, Westville Campus, South Africa.
}

Received 27 January, 2015; Accepted 29 September, 2015

\begin{abstract}
Medicine availability is an important aspect of providing good quality healthcare. Some medicines are available in doses that are not suitable for a specific population group such as children or geriatric patients. Manipulation of the existing medication is undertaken instead. Studies on the practices, frequency and extent of extemporaneous compounding have been undertaken in countries such as New Zealand, Australia, United States of America and Mexico. No data exists for South Africa. Therefore the aim of the study was to explore the level of extemporaneous compounding skills at public hospital level, and to assess whether compounding is occurring in their pharmacies. A quantitative research approach applying the cross-sectional research design was used to determine the extemporaneous compounding practices in a tertiary hospital pharmacy. Twenty five pharmacists responded to a questionnaire on their knowledge and practices. Data was collected from 691 batch records and prescriptions dating from the January 1, 2008 to December 31, 2009 to determine the frequency and extent of extemporaneous compounding. Nearly all (96\%) of the responding pharmacy personnel indicated having received compounding training skills through supervision by experienced pharmacists. Seventy two percent explained that they compounded medication due to the unavailability of certain prescribed drugs. In addition, $60 \%$ of the respondents confirmed that the expiry date is personally developed. The most compounded medicines were dermatological preparations $(46.60 \%)$. The findings suggest that there seem to be insufficient skills within the tertiary hospital pharmacy staff for small scale compounding and identified the need for more research into this practice.
\end{abstract}

Key words: Extemporaneous, compounding, quality, quality assurance.

\section{INTRODUCTION}

The global and chronic lack of licensed medicines and appropriate dosage forms and strength for specific groups of patients is widespread, and has sparked the initiatiation of extemporaneous compounding practice worldwide (Brion et al., 2003; Giam et al., 2012). The need for extemporaneous compounding is also observed

*Corresponding author. E-ma il: sulemanf@ukzn.ac.za. Tel: +27 312607941.

Author(s) a gree that this article rema in perma nently open access under the terms of the Creative Commons Attribution License 4.0 Intemational License 
in cases of rare disease conditions that require tailormade therapy for a specific patient (Salgado et al., 2005; Spark, 2014). Other reasons for extemporaneous compounding are sensitivity/allergy to certain excipients and preservatives, different dose availability or different routes of administration required, or compliance problems related to the use of some medications, for example, palatability of the formulation/medicine (Feldschuh, 2008; Spark, 2014). The dose or the dosage form registered as such might not be suitable or appropriate for paediatrics, geriatrics, or those adults who are unable to swallow solid dosage forms, and those in whom medication is administered in a liquid form through naso-gastric tubes due to poor swallowing reflexes necessitating extemporaneous compounding (Standing and Tuleu, 2005; Kairuz et al., 2007a; Giam et al., 2012).

All these problems, coupled with pervasive lack of commercially available suitable drugs, have thus resulted in the need to make use of extemporaneous preparations in most hospital pharmacies. Giam and McLachlan (2008) defined extemporaneous compounding as the extemporaneous preparation, mixing, packaging or labeling of a drug as the result of a practitioner's prescription drug in order to meet an individual patient's need. They may be formulated from existing dosage forms (Brion et al., 2003; Haywood and Glass, 2007; Spark, 2014), which entails crushing commercially available tablets and capsules contents into a suitable liquid dosage form, with the aim of providing accessible essential medications to among others patients who are unable to swallow solid dosage forms (Nahata and Allen, 2008).

On the other hand, in the United States of America, the Food and Drug Administration (FDA) regards traditional pharmacy compounding as the extemporaneous combining, mixing, or altering of ingredients by a pharmacist, in response to a physician's prescription to create a medication tailored to the specialized medical needs of an individual patient. Traditional compounding typically occurs when a regulatory body-approved drug is unavailable or a licensed healthcare provider decides that an approved drug is not available in the appropriate dosage form for his or her patient's medical needs. Extemporaneous compounding may again occur in a case of the manipulation of the product's strength suitable for adult use, where the prescriber needs a lesser strength for an infant (Kairuz et al., 2007b).

Improperly compounded, adulterated drugs have the potential to cause significant harm to patients (Food and Drug Administration, 2006).

The global lack of documented and standardized formulae poses a high risk to patients as there may be variation in manufacturing methods used. Furthermore, the excipients used may differ greatly, and their effect on the stability and quality of the compounded product cannot be guaranteed (Shah et al., 2013). The Food and Drug Administration survey (Food and Drug Administration, 2006) emphasized that without strict observance of good manufacturing practice guidelines, it is possible to have miscalculations of the respective quantities of each ingredient, and this could be problematic especially where the system and processes are not tightly regulated. There have been a number of problems reported in recent years due to a lack of quality assurance processes. For example, in the United States of America a 2012 meningitis outbreak was tied to the now-shut New England Compounding Center in Framingham that killed at least 64 people and sickened 750 more. Inspections subsequently found unsanitary conditions at the company's facility (Shaughnessy, 2012). Between March and April 2013, the FDA requested a number of voluntary nationwide recalls for compounded products due to a lack of sterility assurance (Eisler and Schnaars, 2014). In South Africa in the last decade, problems were also detected with the mixing of traditional medicines and conventional drugs that had serious adverse effects (Snyman et al., 2005).

While most countries such as New Zealand (Kairuz et al., 2007a), Australia (Feldschuh, 2008), United Kingdom (Steward et al., 2007), United States of America (Treadway et al., 2007), the Netherlands (Giam and McLachlan, 2008) and Mexico (Flores-Perez et al., 2008) have undertaken studies to determine the skills of staff compounding medicines, as well as the frequency and extent of extemporaneous compounding, no data exists for South Africa. Such studies are essential for improving the care of patients, especially because of the high prevelance of HIVIAIDS South Africa is facing, and especially for the compounding that takes place for paediatric preparations. Pharmacists in the hospital settings are responsible for assuring the quality of all compounded preparations according to Nunn (2003).

This is largely due to their professional obligation and training enabling them to perform extemporaneous compounding and also being cautious in making sure that all formulations are followed to the letter in order to maintain acceptable compounding standards. Compounding skill is a required competency for practice for registered pharmacists in many countries, more especially in New Zealand (Kairuz et al., 2007a). The purpose of this pilot study was to determine if the practice and extent of compounding, to determine the skills set and capacity of the staff compounding medicines, in order to raise the standards of compounding and prevent the risk of patient harm.

\section{MATERIALS AND METHODS}

In this study extemporaneous preparations were defined as products made or compounded in a pharmacy on a small scale to 
meet a specific patients' specific requirements of all age goups (Brion et al., 2003; Gross, 2005; Schultz, 2007), or a tailored therapy for a specific patient. For this study, the practice of extemporaneous compounding focused on small scale manufacture of preparations, using raw materials, or commercially available dosage forms, to reformulate a suitable dosage form at an appropriate strength for a specific patient of any age group. This was a cross sectional descriptive pilot study, that took place in the Polokwane Municipality, which is in the Capricorn District of Limpopo Province, South Africa, and has $44 \%$ of the district's (Statistics South Africa, 2007). The tertiary hospital complex (made up of two hospitals) in the province was purposively selected as the site of study as it is a referral hospital with medical specialty mix at its disposal and it had 450 beds. The were 59 pharmacy personnel consisting of pharmacists, community pharmacists, pharmacy interns, pharmacist assistants and auxillary service officers (in 2009) that were present in the two pharmacies (Limpopo Department of Health and Social Development, 2008). Thus, a purposeful sampling was conducted to select the pharmacists. A self-administered close-ended and open-ended questionnaire was designed to collect information from pharmacists and pharmacy managers for characterization of the compounding practice processes for Quality Assurance on seven items, namely;

(a) The pharmacist's demography

(b) The education level

(c) Class of personnel

(d) Training methods

(e) Policies and procedures for extemporaneous compounding

(f) How expiry dates are determined

(g) The challenges of compounding

(h) The most common reasons for extemporaneous compounding.

The questionnaire was adopted from Treadway et al. (2007), and then modified to include additional variables, such as the challenges and reasons for extemporaneous compounding. The researchers elected to use self-administered questionnaires so that it could be completed during the pharmacists' spare time and final collection was after six months. The participants' identification was coded for anonymity. Pharmacists willing to participate in the study signed the consent form and completed the questionnaire after information about the study was explained by the researcher. The study was conducted between January 1, 2008 and December 31, 2009. In order to assess the frequency and the extent of extemporaneous compounding in the two hospital pharmacies of the Polokwane Municipality, retrospective data collected on a modified data sheet designed by Kairuz et al. (2007a) was used. All the batch records from January 1, 2008 to December 31, 2009 were purposively sampled. The data collection sheet was amended to provide the following information: The name of the compounded drug, quantity produced, route of administration, dosage form, storage conditions, expiry date, and date of preparation (to ensure that the study date inclusion criteria was met). Retrospective data were collected on site using the data collection sheet to determine the number of extemporaneously compounded preparations prescribed out of the total number of prescriptions for each month during the period of the study, January 2008 to December 2009. This measured the extent of extemporaneous compounding. A purposeful sampling was conducted to select the prescriptions. Delays in accessing data, as well as data being unavailable for the period beyond December 2009 (batch records being lost and prescriptions being filed elsewhere) resulted in delays in data analyses and publication of results. However, there have been no new interventions in terms of policies on extemporaneous compounding, further education requirements in this area, or in terms of pharmacy personel employed at the study hospital. As such the results are still valid for the current period.

All extemporaneously compounded preparations in the data collection sheet were coded on a coding sheet and captured on the Microsoft Excel. All variables for assessing the frequency and the extent of extemporaneous compounding were coded and captured as well on the Microsoft Excel. The scale questions from the pharmacist questionnaire was coded from " 1 " to " 4 " with " 1 " representing "Never" and "4" representing "Always". "Yes" and "No" were coded "1" "2", respectively. All questionnaires were coded and captured into Microsoft Excel. The analysis consisted of descriptive and analytical components. This was done using Statistics Package for Social Sciences (SPSS Version 20, 2011).

\section{Ethical considerations}

Written permission to conduct the study was sought from and granted by the Research Ethics Committees (HSS/0984/2009) of the University of KwaZulu-Natal, the Limpopo Provincial Department of Health and Social Development and the hospital Chief Executive Officer (CEO).

\section{RESULTS}

Fifty-nine questionnaires were distributed to tertiary hospital pharmacy personnel, Only 25 were returned, resulting in $42.37 \%$ response rate. The low response rate was due to non-availability of respondents to participate because they verbally mentioned large daily workload as a reason. The demographic profile of the sample indicated that the majority of the pharmacists were female (56\%) (Table 1). Pharmacy personnel in the age range of 20 and 30 years made up 36\% of the sample, while those in the age range 31 to 40 comprised $32 \%$ of the sample.

\section{Expertise of personnel}

There was an equal distribution of senior pharmacists (20\%) and registered pharmacy assistants (20\%) in the personnel cartegory with principal pharmacists and pharmacist interns making up the next biggest percentage (16\% each). With regard to the pharmacists' level of education, $64 \%$ indicated Bachelor of Pharmacy to be their highest level of education. There were $32 \%$ that still had the previous qualification of Honours in Pharmacy. Almost all of the pharmacists (96\%) reported receiving compounding skills training, with $80 \%$ agreed to be receiving training through supervision by experienced pharmacists as compared to $64 \%$ that stated they received their experience via personal experience. Training content (Table 2) included information sourcing (56\%), use of reference materials (68\%), use of equipment like weighing scales, compounding tile for creams and ointments (96\%), labeling according to recommended guidelines (92\%), compounding record 
Table 1. Demographic profile as percentages of the total sample.

\begin{tabular}{llcc}
\hline Variable & Number $(\mathbf{n}=\mathbf{2 5})$ & Frequency & Percent \\
\hline \multirow{2}{*}{ Gender } & Female & 14 & 56 \\
& Male & 11 & 44 \\
Race & Black & & \\
& White & 23 & 92.0 \\
& & 2 & 8.0 \\
Age (years) & $20-30$ & & 36.0 \\
& $31-40$ & 9 & 32.0 \\
& $41-50$ & 8 & 28.0 \\
& $51-60$ & 7 & 4.0 \\
& & 1 & \\
& Principal pharmacist & & 16.0 \\
Personnel category & Senior pharmacist & 4 & 20.0 \\
& Pharmacist & 5 & 12.0 \\
& Phamacist intern & 3 & 16.0 \\
& Registered pharmacy assistant & 4 & 20.0 \\
& Community pharmacist & 5 & 8.0 \\
& Pharmacy assistant basic & 2 & 8.0 \\
& & 2 & 4.0 \\
Personnel qualification & & 64.0 \\
& Doctorate & 1 & 32.0 \\
\hline
\end{tabular}

Table 2. Compounding skills training areas.

\begin{tabular}{lcccc}
\hline Which training areas are covered in your training? & Agree (\%) & Frequency (n=25) & Disagree (\%) & Frequency $(\mathbf{n}=\mathbf{2 5})$ \\
\hline Sourcing formulation & 56 & 14 & 40 & 10 \\
Use of references & 68 & 17 & 32 & 8 \\
Use of equipment, mortar and pestle, balances etc. & 96 & 24 & 4 & 1 \\
Labeling & 92 & 23 & 8 & 2 \\
Compounding record keeping & 92 & 23 & 8 & 2 \\
Formulation record keeping & 80 & 20 & 20 & 5 \\
Aseptic technique & 12 & 3 & 88 & 22 \\
Other & 24 & 6 & 76 & 19 \\
\hline
\end{tabular}

keeping (92\%), and formulation record keeping (80\%). The study found $92 \%$ availability of compounding policies and procedures for the production of the same product for different batches. Furthermore, there were no proof of records kept on regular calibration of electronic weighing scales (76\%) and maintenance (72\%). The pharmacy personnel were asked how often the following listed records (Table 3) were included in the documentation of their pharmacy.Documentation for compounding comprised of a manufacturing batch record and are always kept (80\%), and compounding formula and procedures at $72 \%$ (Table 3). A logbook of all compounded items is always kept (64\%).

The study further revealed that maintenance of weighing scales is never carried out at $64 \%$. Table 4 below shows resources which the pharmacy personnel use for obtaining compounding formulations. The source of compounding formulations were either from published literature $(40 \%)$ or self-reports on in-house formulations which are personally developed (28\%). According to the pharmacists, the hospital has compiled and used a formulation document containing the formulation of a 
Table 3. Documentation of compounding in the hospital.

\begin{tabular}{lcccc}
\hline $\begin{array}{l}\text { How often are the following listed records included in } \\
\text { the documentation of this pharmacy? }\end{array}$ & Never (\%) & Sometimes (\%) & Often (\%) & Always (\%) \\
\hline Manufacturing batch records & 4 & 8 & 8 & 80 \\
Compounding formulae and direction for compounding & 8 & 4 & 16 & 72 \\
A log of all compounded items* & 4 & 8 & 20 & 64 \\
Balance maintenance log books* & 64 & 4 & 12 & 16 \\
Standard Operating Procedures* & 12 & 8 & 24 & 52 \\
\hline
\end{tabular}

* Missing values for these variables is $4 \%$.

Table 4. Resources used for obtaining formulations in hospital pharmacy.

\begin{tabular}{lcc}
\hline $\begin{array}{l}\text { What resources do staff members use for obtaining } \\
\text { formulations in compounding? }\end{array}$ & Percentage & Frequency \\
\hline Published literature & 40 & 10 \\
Other hospitals & 16 & 4 \\
Other pharmacies & 4 & 1 \\
In-house; personally developed & 28 & 7 \\
Missing & 12 & 3 \\
\hline
\end{tabular}

Table 5. Establishing expiry dates.

\begin{tabular}{lcc}
\hline \multirow{2}{*}{ Establishment of expiry dates } & \multicolumn{2}{c}{$\mathbf{N}=\mathbf{1 9}$ (6 missing, 24\%) } \\
\cline { 2 - 3 } & Agree (\%) & Frequency \\
\hline In-house stability testing & 4 & 1 \\
External stability testing & 4 & 1 \\
Recommendations from other hospital pharmacies & 4 & 1 \\
Recommendations from other pharmacies & 4 & 1 \\
Personally established dates & 60 & 15 \\
Missing & 24 & 6 \\
\hline
\end{tabular}

product, method of preparation, quantities prepared, storage temperature, date of compounding and shelf-life for each product.

In terms of determining an expiry date, results shown in Table 5 revealed that $60 \%$ of the respondents confirmed that the expiry date is personally developed. There was inconsistency in documenting these dates. No stability and quality control tests are carried out to assess physical, chemical and microbiological changes or for the suitability of the formulation in terms of the active material content and shelf-life.

The pharmacy personnel were asked about the challenges they encounter in the preparation of compounded product, and they strongly agreed (96\%) that formulations were available in the pharmacy and that calculations were not (84\%) a challenge.
Standard Operating Procedures were not revised, however (72\%). The main reasons for compounding were unavailability of prescribed drug (72\%); unsuitable dosage form (44\%) and unsuitable route of administration (32\%).

\section{The extent and frequency of compounding}

The results for the extent of compounding were assessed by reviewing 691 batch records. There was an average of $27.64 \%$ preparations compounded per month with the compounding frequency of $57.6 \%$ in 2008 and $42.4 \%$ in 2009. Solutions accounted for more than $43.9 \%$ of the most frequently compounded dosage formulation. This study revealed that dermatologicals, that is, creams and ointments totalling 33.0 and $13.60 \%$, respectively are 
mostly compounded at the hospital. The most compounded products were Betamethasone (27.9\%) and Corticosteroid (32.9\%). The shelf-life given for extemporaneously compounded preparations was found to be ranging from 6 months (66.3\%), 3 months (14.5\%) and 12 months (9.8\%).

A considerable number (98.30\%) of extemporaneously compounded preparations were reported to be stored below $25^{\circ} \mathrm{C}$. Only $1.70 \%$ were refrigerated at $2-8^{\circ} \mathrm{C}$. The refrigerated solutions were found to be the oral solutions containing minerals for supplementation. The other dosage forms and other oral and non-oral solutions were stored below $25^{\circ} \mathrm{C}$. Most of the preparations were extemporaneously prepared from commercially available drugs where the prescriber needed lesser strength for a specific patient condition, irrespective of the patients' age.

\section{DISCUSSION}

Compounding errors are an emerging and serious problem. Pharmacists hold a unique position as health professionals who are formally trained in compounding medications and licensed to dispense them. This research attempted to gain an understanding of compounding practices in the tertiary hospital pharmacies in the Polokwane Municipality, as a follow up of Treadway et al. (2007) who noted that there are serious questions about the quality of compounded preparations. Most of the pharmacists in this study received their training as part of the undergraduate curriculum. Eley and Birnie (2006) indicated that pharmacy students do not adequately retain compounding knowledge and skills, but that pharmacy students' level of competency and retention of knowledge with respect to compounding capsules is not adequately retained after a 12-month hiatus. Different findings of the training on compounding skills (69\%) were reported in Texas by Treadway et al. (2007). Treadway and colleagues cited a study by Morris et al. (2003) with a training rate of $96 \%$ for pharmacists and $89 \%$ for technicians. A key finding of this study is the limited training in aseptic technique, which if not followed properly could result in contamination of compounded products. There is thus a need to look at competency assessments for compounding pharmacists as well as continuous professional development in this area.

This study indicated that extemporaneous compounding is not subjected to a quality control procedure beyond calculations, ingredients checking and visual inspection which is in agreement with the findings from Donnelly et al, (2008). This is in contrast to the quality control operations pertaining to proprietary products manufactured by the pharmaceutical industry, where GMP standards are followed Donnelly et al. (2008). The study found $92 \%$ availability of compounding policies and procedures, compared to the findings by Treadway et al. (2007) of $71 \%$ of pharmacies in Texas. In Treadway et al. (2007) study, two third of the pharmacies responded to have no policies and procedures and did not provide staff training. This study results also contradict Treadway et al. (2007) findings as in that study, $82 \%$ of pharmacists used published literature and $40 \%$ of formulations were personally developed despite the emergence of more established sources for compounding formulations. Treadway et al. (2007) found that unsuitable dosage forms as a reason for compounding was found to be the lowest (16\%) and cost at 50\% was the main reason for compounding. This study found that the unavailability of the prescribed medicine was the main driver for compounding. There have been attempts in the past decade according to Treadway et al. (2007) to raise the standard of all compounding practices through the efforts of the United States Pharmacopeia (USP) and the American Society of Health-System Pharmacists (ASHP) through ASHP guidelines on Quality Assurance for Pharmacy - Prepared Sterile Products in 2000. More recently, USP has put further procedures and requirements on compounding non-sterile and sterile preparations in an attempt to help raise the standards of compounding and prevent the risk of patient harm. This is largely absent in South Africa.

This study indicated a frequency of compounding at this hospital of between 40 and $50 \%$. In the United States, it has been estimated that approximately $1 \%$ of prescriptions are compounded, representing nearly 30 million prescriptions annually. A similar estimate has been made for compounded prescriptions produced in Australia (Giam et al., 2012). This study revealed that pharmacy compounding consists mostly of dermatological products and dermatological dosage forms. In a study by Buurma et al. (2003) who evaluated the frequency of compounding in the Dutch community pharmacies, the findings were that it consisted largely by dermatological preparations and dermatological dosage forms. A contrary result was found by Kairuz et al. (2007a) in the New Zealand hospital sample survey in determining the extent and nature of compounding, where oral supensions were the most compounded dosage form with a reformulation of Omeprazole being the most frequently compounded drug.

The shelf-life given for extemporaneously compounded preparations was found to be 3 months, 6 months and 12 months. However, there are some products which should be used within $24 \mathrm{~h}$ of preparation. According to Brion et al. (2003), an unpublished United Kingdom survey showed that $54 \%$ of 112 pediatric extemporaneous formulations had inadequate data on shelf-life. This is due to the extensive research that will need to be undertaken to establish the suitability of the formulation 
on its stability. Lack of time, expertise and facilities in hospital pharmacies, among others, limit the undertaking of such research.

\section{CONCLUSION AND RECOMMENDATION}

This pilot study has indicated that compounding is occuring in South Africa, but there is a need for training and for a standardized compendium of formulation for quality assurance reasons. There is a need for professional organizations to play a role as a source of compounding formulations and quality assurance guidelines. This could be a way to increase the quality of available formulas by using a central source of information as well as guidelines for expiry date determination and equipment caliberation among other quality assurance processes. However, as this is a pilot, there is a need for more research in the compounding practices in both public and private sector facilities in South Africa in order to avoid any compounding contaminations or errors that could result in patient harm or even death.

\section{Conflicts of interest}

The authors declare that there are no conflicts of interest.

\section{ACKNOWLEDGEMENTS}

We thank Mr GT Mahlatsi for the assistance in conceptualising the study, The University of Limpopo for financial assistance, The Limpopo Provincial Department of Health and Social Development for granting me permission to conduct the study in the province.

\section{REFERENCES}

Brion F, Nunn AJ, Rieutord A (2003). Extemporaneous (magistral) preparation of oral medicines for children in European hospitals. Acta Paediatric 92:486-490.

Buurma $\mathrm{H}$, de Sme TP, van den Hoff OP, Sysling H, Storimans M, Egberts ACG (2003). Frequency, nature and determinates of pharmacy compounded medicines in Dutch community pharmacies. Pharm. World Sci. 25(6):280-287.

Donnelly R, McNally M, Barry J (2008). Is extemporaneous dispensing really in the best interest of patients? Pharm. J. 280:251-254.

Eisler P, Schnaars C (2014). Safety, sanitary problems prompt scores of drug recalls. http://www.usatoday.com/story/news/nation/2014/10/07/compounding -pharmacy-recalls-inspections-contamination/16472741/. Last accessed 21 January 2015

Eley JG, Birnie C (2006). Retention of compounding skills among pharmacy students. Am. J. Pharm. Edu. 70(6):132.

Feldschuh M (2008). Compounding in community pharmacy. Austr. Prescriber 31(2):30-31.
Food and Drug Administration (2006). 2006 Limited FDA Survey of Compounded Drug Products. http://www.fda.gov/Drugs/GuidanceComplianceRegulatorylnformatio n/PharmacyCompounding/ucm204237.htm. Last accessed 21 January 2015

Flores-Perez C, Flores-Perez J, Juarez-Olguin H, Barranco-Garduano D (2008). Frequency of drug consumption and lack of pediatric formulations. Acta Pediatric de Mexico 29(1):16-19.

Giam J, McLachlan AJ (2008). Extemporaneous product use in paediatricpatients: A systemic review. Int. Pharm. Pract. 16:3-10.

Giam JA, McLachlan AJ, Krass I (2012). Characterizing specialized compounding in community pharmacies. Res. Soc. Adm.. Pharm. 8(3):240-252.

Gross Z (2005). Why special manufacturing units are needed now as much as they were ever. Pharm. J. 275:743-744.

Haywood B, Glass A (2007). Stability considerations in liquid dosage forms extemporaneously prepared from commercially available products. J. Pharm. Pract. Res. 37:131-133.

Kairuz T, Chhim S, Hasan F, Kumar K, Lal A, Patel R,Singh R, Dogra M, Garg S (2007a). Extemporaneous compounding in a sample of New Zealand hospitals: A retrospective survey. New Zealand Med. J. 120:1251

Kairuz TE, Gargiulo D, Bunt C, Garg S (2007b). Quality, Safety and Efficacy in the 'Off-Label' Use of Medicines. Curr. Drug Safe. 2:89-95.

Limpopo Department of Health and Social Development (2008). Final Limpopo DHSD 2008/09 -11 Annual Performance Plan - Vote 7. Republic of South Africa: Limpopo Provincial Government.

Morris AM, Schneider PJ, Pederson CA, Mirtallo JM (2003). National survey of quality assurance activities for pharmacy-compounded sterile preparations. Am. J. Health-System Pharm. 60(24):2567-2576.

Nahata MC, Allen LV (2008). Extemporaneous Drug Formulations. Clin. Ther. 30(11):2112-2119.

Nunn AJ (2003). Making medicines that children can take. Arch. Dis. Childhood 88:369-371.

Salgado AC, Rosa ML, Duarte MA, Almeida AJ (2005). Stability of spironolactone in an extemporaneously prepared aqueous suspension: The importance of microbiological quality of compounded paediatric formulations. Eur. J. Hosp. Pharm. Sci. 11(3):68-73

Schultz M (2007). Compounding products in a non-manufacturing environment. Health Sci. Acad. Professional Pract. 7(2):4-6.

Shah M, Sandler L, Rai V, Sharma C, Raghavan L (2013). Quality of compounded topical $2 \%$ diltiazem hydrochloride formulations for anal fissure. World J. Gastroenterol. 19(34):5645-5650.

Shaughnessy AF (2012). Meningitis outbreak shines light on compounding pharmacies. Br. Med. J. 345:e7432

Snyman T, Stewart MJ, Grove A, Steenkamp V (2005). Adulteration of South African Traditional Herbal Remedies. Ther. Drug Monitor. 27(1):86-89.

Spark MJ (2014). Compounding of medicines by pharmacies: An update. Maturitas 78:239-240.

Standing J, Tuleu C (2005). Paediatric formulations - Getting to the heart of the problem. J. Pharm. 300:55-56.

Statistics South Africa (2007). Community Survey, 2007 Basic Results: Municipalities. Statistical release P0301.1.

Steward D, Rou FA, Snaith A, Elliot K, Peter J, McLay HJ (2007). Attitude and experiences of community pharmacists towards pediatric off-label prescribing: A prospective survey. Br. J. Clin. Pharm. 64(1):90-95.

Treadway A, Craddock D, Leef R (2007). Practices of Pharmacies that compound extemporaneous formulations. Am. J. Health Syst. Pharm. 64:1403-1409. 